\title{
AVALIAÇÃO DA PRONTIDÃO DE DADOS PARA A ABERTURA DE DADOS DAS INSTITUIÇÕES PÚBLICAS BRASILEIRAS: CASO DE UMA INSTITUIÇÃO FINANCEIRA PÚBLICA BRASILEIRA
}

\author{
Evaluation of open data readiness of Brazilian public institutions: case of a Brazilian public financial institution
}

\author{
Francisco Tanajura Machado Júnior (1) Remis Balaniuk (2) Ana Paula Bernardi da Silva (3) Vitória \\ Santiago da Silveira (4)
}

(1) Universidade Católica de Brasília, francisco.tanajura@ gmail.com (2) Universidade Católica de Brasília e Tribunal de Contas da União, remisb@tcu.gov.br (3) Universidade Católica de Brasília, anapaula@ucb.br (4) Universidade Católica de Brasília e FAPDF, vitoriasant_go@ hotmail.com

\begin{abstract}
Resumo
O objetivo deste artigo é apresentar os resultados de um estudo de caso para avaliação da prontidão para a abertura de dados de uma instituição financeira pública brasileira. A metodologia utilizada nesse estudo é a do Banco Mundial, denominada Open Data Readiness Assessment (ODRA), com algumas adaptações propostas, a fim de adequá-la às características das instituições da Administração Pública Federal Brasileira. O estudo demonstrou um elevado grau de prontidão da instituição para Dados Abertos (DA). Apesar disso, apontou lacunas a serem preenchidas em relação a um posicionamento mais claro da liderança no tema, ao estabelecimento de uma cultura organizacional em DA e Governo Aberto, a um maior envolvimento da instituição com a comunidade e o público de interesse de maneira ativa, à ampliação das discussões com os gestores dos dados consignados para disponibilização direta pela instituição e à ampliação da disponibilização de dados, seguindo padrões de DA. Além do estudo de caso, o presente trabalho contribui para o cenário atual dos dados abertos governamentais como um todo ao evidenciar a importância que a avaliação da prontidão tem no processo de abertura das instituições públicas e ao fornecer meios para que instituições e órgãos da administração pública brasileira realizem suas próprias avaliações.
\end{abstract}

Palavras-chave: Avaliação de prontidão para dados abertos; Dados abertos; Dados governamentais abertos; Governo aberto

\section{Introdução}

A abertura à participação social nos países democráticos, aliada à evolução do governo eletrônico e às tecnologias, ampliou as discussões sobre a obtenção das informações governamentais. Estas eram, historicamente, restritas ao cidadão pelas agências governamentais e

\begin{abstract}
The main goal of this paper is to present the results of a case study for evaluation of the open data readiness conducted in a Brazilian public financial institution. The methodology used in this study is the World Bank's methodology, called Open Data Readiness Assessment (ODRA), with some adaptations proposed in order to adapt it to characteristics of Brazilian Federal Public Administration institutions. The study demonstrated a high level of readiness of the institution for Open DATA (OD). Despite that, the study pointed out gaps to be fulfilled about a clearer positioning of leadership, the establishment of an organizational culture in OD and Open Government, a greater involvement of the institution with the community and public interest in an active way, the expansion of discussions with the managers of consigned data in order to make data directly available by the institution and the expansion of data availability, following OD patterns. Besides the case study, this paper contributes to the current scenario of open government data as a whole by showing the importance of the assessment of readiness in the opening process of public institutions and to provide means for institutions and Brazilian public administration organizations to carry out their own assessments.
\end{abstract}

Keywords: Open Data Readiness Assessment; Open data; Open government data; Open government

tratadas como de não interesse público (Yu e Robinson, 2012).

Hodiernamente, há um consenso entre as nações democráticas e desenvolvidas de que difundir e compartilhar a informação governamental são essenciais ao exercício da democracia. Restringi-la, ao contrário, resulta em um desequilíbrio de poder, concentrando-o nas 
mãos de quem detém a informação. Esse desequilíbrio gera riscos para o exercício do controle democrático, uma vez que permite ao governante manter seu poder sem ser questionado.

Com o advento das tecnologias digitais a questão da difusão e compartilhamento de informações governamentais rapidamente se apropriou dos recursos de processamento e disseminação de dados eletrônicos, criando o conceito de Dados Abertos (DA) governamentais. A administração pública, em qualquer país minimamente desenvolvido, é fortemente apoiada por sistemas informatizados nos dias atuais. Esses sistemas registram os processos de trabalho cotidianos de órgãos e entidades, receitas e despesas públicas e informações associadas à entrega das políticas públicas à sociedade.

De acordo com Freitas e Dacorso (2014), foi para garantir certo grau de transparência que os órgãos públicos, nos últimos anos, vêm disponibilizando diversos dados financeiros e serviços on-line ao cidadão em suas páginas da internet. Assim, a transparência governamental está intimamente ligada à questão da abertura dos dados governamentais eletrônicos. Por conseguinte, os órgãos públicos tornaram-se mais suscetíveis ao controle social.

No contexto brasileiro, o Governo Federal tem intensificado ações em direção à promoção da transparência, prestação de contas e participação popular na administração pública, por meio da disponibilização de DA. Entre essas ações destacamos a criação do Portal da Transparência, a promulgação da Lei 12.527/2011 Lei de Acesso à Informação (LAI), a integração do Brasil como membro da iniciativa internacional - conhecida como Parceria para o Governo Aberto (Open Government Partnership - OGP), a criação da Infraestrutura Nacional de Dados Abertos (INDA) e do Portal Brasileiro de Dados Abertos (dados.gov.br) (Brasil, 2012; Zymler, 2014).

A LAI, em seu art. $1^{\circ}$, ao estabelecer a obrigação de fornecer acesso às informações públicas ao cidadão, não faz distinção de esfera, poder ou entre a administração direta e a indireta. Modesto et.al (2014) salienta a importância do compartilhamento de dados públicos no seguinte trecho:

Importantes organismos internacionais, como a Organização das Nações Unidas (ONU) e a Organização dos Estados Americanos (OEA), reconhecem que o acesso à informação é um direito fundamental a todos os cidadãos. $\mathrm{O}$ Brasil, a partir de novembro de 2011, também passou a ter esse entendimento. Toda informação que esteja sob tutela do estado é sempre pública e seu acesso não pode ser restrito, salvo alguns poucos casos específicos. Com isso, o Estado tem o dever de guardar, organizar, gerenciar e dar acesso às informações por ele geradas. (Modesto et.al, 2014)

No entanto, a Administração Pública Federal (APF) ainda encontra dificuldades no processo de disponibili- zação dos dados abertos. Zymler (2014) aponta algumas delas:

A falta de sustentabilidade das iniciativas geradas, em especial, das soluções construídas pela sociedade ou de forma colaborativa; falta de pessoal e de governança na gestão do processo; e falta de padronização". (Zymler, 2014, p.73)

Ademais, a maioria das demandas do cidadão são atendidas de maneira reativa e voltadas para suprir as necessidades legais (Cavalcanti et al., 2013). Pouco também se tem investido na relação entre os publicadores dos DA e seus usuários, de forma a buscar o fortalecimento da política de DA e a potencialização dos seus benefícios (Beghin e Zigoni, 2014).

Obviamente o cenário brasileiro é influenciado por fatores de natureza, escala e importância muito distintos. Legislação adequada e pressão social são, por exemplo, fatores de grande importância para o sucesso das políticas de abertura de dados governamentais, mas que precisam ser analisados em escala nacional. Outros fatores, como governança e infraestrutura tecnológica, podem também ter grande efeito nos resultados de uma iniciativa específica de abertura de dados, mas operam em uma escala bem menor, a nível institucional. Estudar esses fatores relevantes na escala institucional nos interessa, pois permite levantar sugestões de medidas e estratégias disruptivas rapidamente adotáveis mais facilmente, já que dependem somente de uma cadeia decisória interna à instituição.

No contexto de escala institucional, a primeira constatação que merece destaque é que a abertura de seus dados não é um ato isolado. Este processo começa bem antes da implementação de ações práticas, que requer diversas etapas de preparação, discussão, planejamento e estruturação. A abertura de dados é mais do que uma questão ou uma perspectiva técnica e deve ser tratada como uma plataforma completa, um ecossistema que inclui componentes políticos, legais, avanços tecnológicos (Sandoval-Almazán, 2011) e mecanismos de classificação dos dados segundo diversos critérios.

Para abrir os seus dados, uma instituição deve estar preparada para disponibilizá-los a um público amplo e diverso, de maneira a atender às demandas não só dos cidadãos, mas também dos diversos intermediários de dados (World Bank, 2015). Para isso, o processo de preparação para a abertura dos dados envolve mudanças institucionais, em termos de cultura, metodologia, capacitação (interna à instituição e dos usuários), envolvimento dos cidadãos, infraestrutura tecnológica e financiamento da inovação. A essa preparação chamamos de prontidão para a abertura de dados.

Analisar a prontidão é verificar em que situação se encontra o processo de abertura de uma instituição para disponibilizar DA, antes mesmo que a instituição comece a abrir os seus dados. Assim, a importância da análise da prontidão, diferentemente da análise das 
iniciativas de abertura já em curso, está em verificar se as condições necessárias existem e o quanto elas estão aderentes às boas práticas de DA.

A LAI, em seu art. $1^{\circ}$, ao estabelecer a obrigação de fornecer acesso às informações públicas ao cidadão, não faz distinção de esfera, poder ou entre a administração direta e a indireta. Contudo observa-se que os avanços obtidos nesses diferentes contextos variam enormemente, posto que no Estado brasileiro a administração indireta difere substancialmente da direta pela sua diversidade e descentralização. Enquanto na administração direta a nível federal resultados expressivos têm sido obtidos, nas esferas estadual e municipal assim como na administração indireta os avanços tem sido muito mais tímidos e bem mais desiguais. Portanto, a investigação sobre a prontidão para a abertura de dados é ainda mais relevante tendo como foco os contextos mais problemáticos, para que se possa verificar neles os fatores de maior criticidade.

No que diz respeito à administração direta é possível discutir a prontidão ao nível de Estado ou de grandes órgãos superiores, enquanto que na administração indireta é preciso descer a análise para o nível das instituições, já que essas possuem outro grau de autonomia administrativa e, embora estejam vinculadas à administração direta, possuem elevado grau de independência em seus processos decisórios. Um exemplo marcante das particularidades da administração indireta são as instituições financeiras públicas. No Brasil, as instituições financeiras públicas têm como missão apoiar o governo no desenvolvimento econômico e social do país. Essas instituições normalmente têm os seus dados protegidos pela Lei do Sigilo Bancário (Brasil, 2001).

A Lei do Sigilo Bancário está impedindo na prática a total transparência de vultosos recursos públicos e cria campo 'obscuro' na transparência das políticas públicas. (Mencarini, 2015, p. 211)

Como integrantes da administração indireta, as instituições financeiras públicas estão subordinadas à LAI e, portanto, naquilo que extrapola o limite da Lei do Sigilo Bancário, elas devem estar preparadas para disponibilizar ao público seus dados de interesse e estar alinhadas com as políticas do Governo para a abertura de dados. Esse aparente conflito entre sigilo e transparência demonstra os muitos dilemas que a abertura de dados impõe aos entes públicos da administração indireta.

O objetivo central desse trabalho de pesquisa foi propor formas de avaliar a prontidão de instituições públicas brasileiras para a abertura de dados, buscando identificar lacunas no seu processo de abertura. Acreditamos que essa avaliação, que pode ser feita pela própria instituição, permite a antecipação de problemas e a correção de rumos, evitando desperdícios de tempo e de recursos e aumentando as chances de sucesso da iniciativa como um todo.
A busca por uma metodologia adequada para avalição da prontidão para abertura de dados nos levou ao Open Data Readiness Assessment (ODRA), proposto pelo Banco Mundial (World Bank, 2013). O ODRA objetiva apoiar o planejamento de ações que uma autoridade governamental deveria considerar, de forma a estabelecer um programa de DA, seja a nível nacional, esferas inferiores ou agências públicas individuais. O processo é baseado em um rápido diagnóstico de oito dimensões consideradas essenciais para o sucesso de um programa de DA. O Banco Mundial disponibiliza gratuitamente em seu site opendatatoolkit.worldbank.org o "Open Data Toolkit" em inglês, francês e russo.

Para o estudo de caso foi escolhida uma instituição financeira totalmente pública que, além de atuar como um banco comercial, tem a missão de atuar na promoção da cidadania e do desenvolvimento sustentável do país. Essa instituição tem sob a sua responsabilidade a custódia e geração de dados de programas sociais e de transferência de renda. Além disso, dispõe de dados públicos importantes que estão submetidos à LAI, como licitações de contratações, execução de programas e despesas de execução orçamentária.

\section{Transparência, governo aberto e dados abertos}

O contexto no qual este estudo se insere, o dos dados abertos governamentais, é marcado por alguns termos de significado não consensual e com certa sobreposição que são governo aberto, governo eletrônico e transparência governamental.

Geiger e Lucke (2012) acreditam que quando os países adotam o governo aberto em suas políticas de prestação de informação aos cidadãos, em geral, utilizam a definição de governo aberto equiparada à de governo eletrônico ou restringem o conceito à utilização das Tecnologias da Informação e Comunicação (TIC) no próprio governo. Isto leva a um entendimento teórico incorreto sobre governo aberto, focado numa transparência limitada à disponibilização de serviços e dados eletrônicos associados diretamente aos seus sistemas administrativos.

Yu e Robinson (2012) afirmam que a imprecisão da definição do governo aberto reduz o poder dos DA, por dar ênfase nos dados provenientes da política de prestação de contas do governo e não enxergar o universo de informações geradas na esfera pública e que poderiam ser reutilizados em prol do bem público.

Indo além, Dassen e Juan (2012) e Ramírez-Alujas (2012) consideram que o governo aberto não está relacionado somente ao uso das TIC ou do governo eletrônico, mas sim conectado a princípios de melhoria na transparência, no acesso à informação, na promoção da participação dos seus cidadãos quanto à elaboração e implementação de políticas públicas, e na promoção da 
criação de oportunidades para a colaboração entre os diversos elementos.

O governo aberto não é só um conjunto de serviços entregues ao cidadão, mas sim uma plataforma participativa, que traz o cidadão para dentro dos processos de tomada de decisão governamentais e que permite a incorporação do potencial das partes interessadas na melhoria de processos e na inovação (Edelmann et al., 2012).

Os dados abertos devem ser tratados como um recurso estratégico entregue à sociedade, indutor de mudanças, com grande potencial para a inovação e a geração de valor. Portanto é preciso manter em perspectiva os objetivos finais da transparência tais como: a melhoria da qualidade da prestação de serviços públicos; a maior eficácia na utilização dos recursos públicos; e, em última instância, a melhoria da sociedade como um todo. Para que esses objetivos sejam atingidos é preciso ir mais longe na questão do governo aberto e incorporar à prática da administração pública e de suas instituições uma série de princípios estruturantes que podem potencializar os recursos disponibilizados a partir dessa abertura e permitir a geração de valor a partir deles. No entanto, é importante observar que a entrega de dados à sociedade deve ser feita à altura do valor estratégico dos mesmos, respeitando os princípios amplamente discutidos e aceitos que regem o conteúdo aberto.

Segundo a Open Knowledge Foundation, uma organização sem fins lucrativos atuante em mais de cinquenta países e que promove o conhecimento livre, o conteúdo aberto é aquele que pode ser livremente acessado, utilizado, modificado e compartilhado para qualquer propósito. Além desse princípio fundamental do conteúdo aberto, uma série de outros princípios norteia, especificamente, a disponibilização de dados abertos da maneira adequada. Entre esses princípios estão: a disponibilização de dados de qualidade e utilidade, em formatos mais inteligíveis e com foco nas necessidades dos usuários, para que cidadãos - potenciais utilizadores de serviços - tomem melhores decisões (Dassen e Juan, 2012; Ramírez-Alujas, 2012); e a publicação de dados de forma proativa, em formatos legíveis por máquina e sob licenças livres, de modo que qualquer cidadão possa acessá-los e reutilizá-los nos seus diferentes contextos e necessidades (Dietrich et al., 2012; World Bank, 2013; Davies, 2014; Gurin, 2014).

Não se deve esquecer ainda a questão da continuidade e da sustentabilidade das políticas associadas à transparência. O alcance e o impacto de uma política de informação eficaz para promover um governo aberto requerem vigilância e governança constantes, seja a nível administrativo e operacional, seja a nível político, de forma a garantir que não haja retrocessos ou descontinuidades.

Por fim, é preciso evitar uma visão excessivamente restritiva do universo de informações governamentais que a abertura de dados deve atingir. Embora devam existir limites nessa disponibilização, é preciso evitar interpretações excessivamente conservadoras dos limites previstos em lei. Da mesma forma, a abertura não deve se contentar com a disponibilização de dados administrativos e financeiros, mas buscar nas bases de dados governamentais existentes todas aquelas com conteúdo potencialmente útil para a sociedade.

Vencer o desafio da abertura de dados de forma ampla e irrestrita não tem sido uma tarefa fácil para os governos democráticos em todo o mundo. Para um observador desavisado pode parecer uma questão puramente tecnológica, mas não é. Há a necessidade de: implantar normas, legislações e políticas para garantir a perpetuidade das ações; apoiar quem consome esses dados; catalogar as informações a serem disponibilizadas; adotar padrões quanto à segurança, qualidade, respeito à privacidade e confiabilidade; implementar infraestrutura de TIC; adequar sistemas internos; e identificar dados que realmente sejam úteis ao cidadão. Porém tudo isso leva tempo e consome recursos.

\section{Prontidão para abertura de dados governamentais}

O processo de abertura de dados, seja ele a nível de governo ou institucional, exige visão estratégica de longo prazo, liderança e governança. A definição de planos e estratégias realistas e robustas é necessária desde as fases iniciais, de forma a preparar um caminho que garanta uma abertura ampla e sustentável. Embora a base para o desenvolvimento dessas estratégias possa variar de país para país, o objetivo final é sempre o mesmo: ofertar dados produzidos pelo Governo, ou em seu nome, para que o cidadão possa reutilizá-los a fim de gerar novos valores de negócios.

De acordo com Sandoval-Almazán (2011), governos em diferentes níveis - local, estadual e federal - e com diferentes graus de desenvolvimento seguiram orientações diversas e interpretações próprias sobre a ideia de governo aberto e disponibilização de Dados Governamentais Abertos (DGA), introduzindo políticas específicas e prioridades próprias ao seu contexto. No entanto, poucos deles tinham referências adequadas ou experiências anteriores para embasar suas decisões.

A falta de referências e a diversidade de entendimentos levaram os governos a fazerem inúmeras opções equivocadas que geraram dificuldades, atrasos, erros operacionais, desperdício de recursos públicos e problemas legais. Essas dificuldades demonstram a necessidade de se preparar um ambiente adequado para o processo de abertura, abordando as questões essenciais desde o início desse processo. A adequação desse ambiente é o que chamamos de prontidão para a abertura de dados.

A prontidão de um governo para DA, vai além da disponibilização de dados em si, envolve todo o

Machado Júnior, Francisco Tanajura; Balaniuk, Remis; Silva, Ana Paula Bernardi da; Silveira, Vitória Santiago da. Avaliação da prontidão para abertura de dados das instituições públicas brasileiras: caso de uma instituição financeira pública brasileira. // Brazilian Journal of Information Studies: Research Trends. 12:1 (2018) p.06-20. ISSN 1981-1640. 
ecossistema de DA, que inclui outras dimensões importantes como liderança, quadro político e jurídico, instituições, infraestrutura do Estado e das comunidades de usuários-desenvolvedores, universidades e setor privado (World Bank, 2015). A prontidão pode ser entendida como uma construção e um desenvolvimento constante (Sandoval-Almazán, 2011).

Davies et al. (2015) tratam a prontidão para a abertura de dados governamentais como uma questão que extrapola as fronteiras da administração pública. O estudo conclui que a prontidão dos Estados, cidadãos e setor privado progrediu pouco nos últimos anos, principalmente por ausência de políticas eficazes para DA, capazes de aumentar o grau de colaboração entre o Estado, o setor privado e a sociedade civil. Para transformar esta situação, segundo o estudo, é necessário um equilíbrio entre os governos com capacidade de criar, gerenciar e publicar dados e terceiros com habilidades técnicas, liberdades e recursos para a utilização dos dados como uma ferramenta para a mudança. Os governos que se concentram exclusivamente no aumento da oferta de DA são susceptíveis de não alcançar os benefícios de DA (Davies et al., 2015).

No estudo da prontidão não deve faltar o aspecto legal e a salvaguarda dos direitos do cidadão. Ao desenvolver estratégias de DGA, os decisores políticos e técnicos devem ter em mente o direito à informação, mas também a salvaguarda da privacidade pessoal e as questões de segurança nacional. Entretanto, essa preocupação não pode se tornar motivo para não disponibilizar dados de forma irrestrita. Portanto, os governos precisam desenvolver mecanismos para a identificação de questões legais centrais, a fim de equilibrar o direito à privacidade e o direito à informação (UN, 2014).

Em função do exposto, conclui-se que a contínua avaliação da prontidão é uma das questões chaves para o sucesso de um processo de abertura dados. Ela auxilia no entendimento e na orientação dos decisores políticos e técnicos no planejamento, na implementação e na gestão das iniciativas de DGA.

\section{Adaptação da metodologia de avaliação da prontidão das instituições públicas brasileiras para a abertura de dados}

A metodologia ODRA foi construída para ser utilizada na avaliação da prontidão tanto de um governo nacional quanto de um governo regional ou municipal, em uma única instituição ou em um único setor. Contudo, algumas das questões que a metodologia analisa necessitam ser adaptadas às circunstâncias particulares de cada contexto, que podem estar ligadas a questões legais, organizacionais ou normas específicas.

A $O D R A$, na sua versão 3.1, contém um arcabouço de conceitos e questões levantadas em oito dimensões essenciais para o sucesso de um programa de DA. Esse conjunto de conceitos e questões permite avaliar se um país ou até uma instituição reúnem as condições de prontidão para abertura de dados. A partir de cada conceito em cada dimensão, são levantadas evidências positivas ou negativas que podem apontar a prontidão ou lacunas que necessitam ser preenchidas, para o sucesso de uma iniciativa. Além disso, a ODRA pode ser utilizada em vários estágios de maturidade de uma iniciativa ou de um programa de DA, como nas primeiras etapas de preparação, nas etapas de desenvolvimento quando os movimentos iniciais já foram feitos, ou para fazer um balanço do desenvolvimento até uma determinada etapa.

A proposta da versão 3.1 da $O D R A$, que foi traduzida e adequada para o contexto aqui estudado, serviu de base para a realização da pesquisa na instituição pública escolhida. A adaptação buscou relacionar as questões originalmente direcionadas ao Presidente ou Primeiro Ministro da nação, para o Presidente ou Diretor Presidente de uma instituição pública brasileira. Da mesma forma, adequamos as questões direcionadas aos ministérios ou órgãos da administração do país para as diretorias ou departamentos da instituição a ser avaliada. Ocorre que em algumas questões, pela amplitude de suas características, devem ser levadas em conta também as orientações ou evidências relacionadas ao país, tais como políticas e legislações, mesmo na avaliação em nível institucional.

Cada dimensão e questão também têm um nível de importância que varia de muito alta a média, não existindo, portanto, questões com baixa importância. A ordenação das diferentes dimensões não é significativa, pois não indica a sua importância relativa. Tanto a importância como a quantidade de atenção a ser dada a cada dimensão terá de ser determinada de acordo com os objetivos de uma avaliação específica. Além disso, as oito dimensões não são projetadas para cobrir todos os elementos possíveis para um programa bemsucedido de DA. Outras questões poderiam ser importantes em circunstâncias locais particulares ou em fases posteriores de um programa DA.

De maneira complementar, para as aferições realizadas pelo próprio Banco Mundial, é elaborado em conjunto com o país ou instituição aferida um plano de ação, que inclui as ações que são mais importantes para o sucesso e a sustentabilidade do programa de DA do avaliado. Essa aferição não costuma produzir um conjunto completo de ações concretas, o que seria visto em um plano de projeto completo, mas aqueles estrategicamente mais importantes.

A seguir serão detalhados os aspectos relevantes das oito dimensões, que foram adaptados dentro da metodologia ODRA:

Machado Júnior, Francisco Tanajura; Balaniuk, Remis; Silva, Ana Paula Bernardi da; Silveira, Vitória Santiago da. Avaliação da prontidão para abertura de dados das instituições públicas brasileiras: caso de uma instituição financeira pública brasileira. // Brazilian Journal of Information Studies: Research Trends. 12:1 (2018) p.06-20. ISSN 1981-1640. 


\subsection{Liderança sênior}

Esta dimensão tem uma importância muito alta, uma vez que o posicionamento da liderança da instituição é um fator que influencia toda a organização. O seu alinhamento com as ações do governo central, em maior ou menor nível, irá determinar o grau de comprometimento da instituição com o programa de DA do governo e o sucesso das iniciativas de DA na instituição.

As questões aqui foram adaptadas para levar em consideração esse alinhamento e influência que o líder maior da instituição exerce em prol da abertura. Para isto, são buscadas evidências que deixem claro o envolvimento do líder na condução da política de DA na instituição, seu alinhamento com a Open Government Partnership e a influência que a instituição exerce no nível político do país.

\subsection{Quadro Político/Legal}

Embora esta dimensão tenha uma importância alta, em muitas questões a instituição está atrelada às legislações e ao quadro político do país. Sob esse aspecto, a adaptação leva em conta tanto o cenário do país, como as referências normativas internas da instituição avaliada. Aspectos como o histórico da instituição em relação ao atendimento à LAI podem ser coletados tanto no portal da Controladoria-Geral da União (CGU), como obtido internamente nas entrevistas.

Nessa dimensão, são vistas questões de tratamento do sigilo da informação específicas para a instituição, as salvaguardas existentes para a manutenção da privacidade como a anonimização dos dados liberados, a proteção dos dados, a comercialização de dados e as licenças utilizadas no âmbito da instituição. Podem ser coletadas evidências tais quais: (1) Qualquer lei existente ou política sobre a liberdade de informação, o direito à informação, ou o acesso à informação; (2) Texto ou transcrição de qualquer promessa política ou posição política em relação a DA, à publicação dos dados públicos ou temas relacionados, como o Governo Aberto ou Liberdade de Informação; (3) Qualquer lei existente ou política sobre o lançamento proativo ou reutilização de informações do setor público; (4) Texto de quaisquer licenças ou condições de utilização existentes para dados do governo; (5) Detalhes de qualquer acordo para o fornecimento de dados governamentais específicos para apenas uma empresa em detrimento de outras, ou quando uma determinada empresa tem o monopólio de um determinado conjunto de dados do governo; (6) Qualquer lei de direitos autorais ou disposição legal que deixe claro que possui dados do governo; (7) Lei de divulgação de estatísticas ou instrumento jurídico semelhante, que descreve quais estatísticas devem ser publicadas e como é que o sistema estatístico é regulamentado; (8) Qualquer lei ou política oficial sobre a proteção da privacidade; (9) Quaisquer leis que limitem o uso das informações produzidas pela instituição pelo público e a sociedade civil.

\subsection{Estruturas institucionais, responsabilidades e habilidades dentro da instituição}

Esta dimensão tem uma importância alta e está voltada para aspectos das habilidades e lideranças de nível intermediário dentro da instituição. Para a adaptação, foi considerada como abrangência a instituição. Podem ser coletadas evidências como: (1) A designação de uma entidade com peso político suficiente para coordenar um programa de Dados Abertos em toda a instituição e garantir que as políticas de Dados Abertos sejam implementadas; (2) A instituição apoia programas e funcionários inovadores; (3) A ideia de Dados Abertos foi introduzida ou socializada entre, pelo menos, alguns departamentos da instituição; (4) Existência de gerentes, CIO, Chief Technical Officer (CTO) ou funcionários permanentes de Dados Abertos designados para desempenhar um papel equivalente entre os principais departamentos interessados (stakeholders); (5) Existência de um programa/projeto conjunto da instituição sobre Governo Aberto; (6) Um processo regular para a gestão de desempenho existe, seja em base do conjunto da instituição ou por departamentos individuais, para medir a qualidade da prestação de serviços ou do desempenho do departamento; (7) Existência de um programa formal de treinamento para os funcionários públicos que aborda TIC e outras questões; (8) Se há um departamento responsável por sistemas de TIC ou de informação na instituição; (9) Existência de mecanismos de redes informais ou eventos para interação entre os funcionários públicos (por exemplo, sobre questões técnicas ou de construção de habilidades); (10) Os documentos que descrevem a governança global da arquitetura de TIC, políticas de entrega, se a instituição tem algum Chief Information Office (CIO), diretor de tecnologia ou pessoal permanente que desempenha um papel equivalente; (11) Os documentos que descrevem o processo regular de gerenciamento de desempenho no âmbito da instituição para medir a qualidade da prestação de serviços ou de desempenho da instituição; (12) Descrição dos programas de formação formais ou informais e mecanismos de rede para os funcionários públicos na gestão e utilização de dados, o envolvimento do cidadão, mídias sociais e outras habilidades relevantes para DA; (13) Lista de sites exemplos da instituição ou dos principais departamentos, serviços eletrônicos e serviços habilitados para telefones móveis relacionados aos dados.

4.4 Políticas institucionais de gerenciamento de dados, processos e disponibilidade de dados

Esta dimensão tem uma importância alta, diz respeito aos conjuntos de dados fundamentais disponíveis que a instituição deseja liberar, que apoiam as prioridades políticas ou institucionais mais amplas. Podem ser coletadas evidências como: (1) Inventário completo, atua- 
lizado e detalhado dos acervos de dados (data holdings); (2) Políticas de gestão de informação e normas coerentes, aplicadas de forma consistente na instituição; (3) Processo para a digitalização de registros em conformidade com as normas internacionais para garantir o acesso e utilização dos dados. (4) Lista completa ou inventário de dados da instituição, se existir; (5) As políticas oficiais ou regulamentares relativas ao gerenciamento de informações, segurança de dados, qualidade de dados, arquivamento de dados e de preservação digital, e as normas que se aplicam em toda a instituição; (6) Regulamento ou política em matéria de contratos que aborda se a instituição mantém a propriedade das informações geradas ou detidas por empreiteiros, parcerias público-privadas ou fornecedores terceirizados; (7) Identificação dos conjuntos de dados disponíveis para um portal de DA. Cada conjunto de dados deve ser avaliado individualmente, tendo em conta tanto a viabilidade de liberação quanto os benefícios de fazê-lo. Para facilitar esta tarefa, a Tabela A.1 do Anexo A de Machado Junior (2015) apresenta uma lista de dados normalmente encontrados em portais de DA;

Existe uma gama de perguntas a serem feitas aos titulares de cada conjunto de dados. Não é esperado que o entrevistado tenha respostas detalhadas para cada uma das questões ou para cada conjunto de dados da instituição, mas podem ser coletadas mais informações sobre os conjuntos de dados antes das entrevistas; o mais provável é que o portal de DA, porventura existente, seja mais rico e amplamente utilizado.

\subsection{Demanda por dados abertos}

Esta dimensão tem uma importância muito alta e objetiva avaliar a demanda por utilização dos dados. Uma forte solicitação por DA é importante para manter a pressão sobre a instituição na liberação de DA úteis à sociedade e na geração de valor de negócio dentro do ecossistema de DA. Nessa dimensão podem ser coletadas evidências como: (1) A política formal da instituição em mídias sociais e/ou no envolvimento do cidadão; (2) Exemplos de processos de consulta participativa para informar as decisões políticas; (3) Exemplos de organizações da sociedade civil bem conhecidas que utilizam tecnologia para capacitar os cidadãos; (4)Existência de defensores de Dados Abertos na sociedade civil; (5) Exemplos de empresas individuais (ou associações comerciais) que procuram/utilizam Dados Abertos; (6) Exemplos de dados do governo que já estejam sendo usados pelo setor privado, pela sociedade civil ou pelos cidadãos de maneira individual; (7) A quantidade, assuntos e pedidos de dados sobre a LAI ou equivalentes em um último período conveniente para a avaliação.
4.6 Engajamento cívico e capacidade para dados abertos

Esta dimensão tem importância alta. Tem o objetivo de avaliar a sustentabilidade das iniciativas de DA. Essas iniciativas são mais sustentáveis e capazes de gerar alto impacto na sociedade quando baseadas numa abordagem voltada para todo o ecossistema de DA, onde os governos e as instituições investem no desenvolvimento de um quadro político/legal forte, na preparação institucional, no desenvolvimento das capacidades dos infomediários ${ }^{1}$ e da própria instituição, no envolvimento dos cidadãos, no financiamento da inovação e na infraestrutura tecnológica.

A adaptação desta dimensão leva em conta o esforço e o papel que a instituição avaliada tem nas ações do governo voltadas para DA. Podem ser coletadas evidências como: (1) Se os departamentos envolvem regularmente os cidadãos, as empresas e outras partes interessadas (stakeholders) para obter feedback e sugestões sobre os seus serviços, decisões ou atividades; (2) Se os departamentos têm um histórico de envolvimento com os desenvolvedores na criação de aplicativos e Serviços Eletrônicos; (3) Se houveram eventos do tipo de cocriação (por exemplo, hackathons, códigos sprints, desafios de apps); (4) Se existe uma massa crítica de desenvolvedores locais, como uma comunidade, e eles são ativos em plataformas de mídia social ou por meio de atividades presenciais; (5) Se financiamentos para projetos iniciais estão disponíveis para os empreendedores e startups; (6) Se já existe uma economia de desenvolvimento de aplicativos (mesmo que pequena) com empresas de desenvolvimento de aplicativos e pessoas usando/comprando/fazendo download de aplicativos; (7) Se há escolas técnicas e universidades com programas de ciência da computação que produzem um número notável de diplomados com cursos técnicos por ano; (8) A política da instituição para as mídias sociais e/ou envolvimento do cidadão; (9) Lista de exemplos de organizações da sociedade civil que utilizam a tecnologia para capacitar os cidadãos ou campeões da sociedade civil para DA; (10) Lista de exemplos em que instituições governamentais promoveram ações regulares junto aos cidadãos, empresas e outras partes interessadas para obter feedback e sugestões sobre os seus serviços, decisões ou atividades, ou têm um histórico de envolvimento com os desenvolvedores na criação de aplicativos e serviços eletrônicos; (11) Lista das principais escolas técnicas e universidades com programas de ciência da computação que produzem um número notável de diplomados por ano, em cursos técnicos; (12) Lista dos principais meios de comunicação, a composição da mídia, principalmente as grandes organizações de mídia ou, se não, lista de principais jornalistas/freelances independentes ou associações de jornalismo. 


\subsection{Financiamento de um programa de dados abertos}

Esta dimensão tem uma importância média alta. Busca avaliar as fontes de financiamento, tanto do lado da demanda como do lado da oferta de DA. A adaptação desta dimensão foi para obter evidências do envolvimento da instituição nos processos de financiamento de DA. Além das evidências descritas no Anexo A, podem ser coletadas evidências como: (1) Se recursos da instituição e/ou outros (por exemplo, doadores ou setor privado) estão disponíveis para financiar um programa de Dados Abertos - incluindo o desenvolvimento e manutenção de um Portal de Dados Abertos - para os primeiros anos; (2) Se a instituição já pensa em como medir o retorno sobre o investimento para o custo de um programa de Dados Abertos - tanto em termos financeiros, quanto em termos sociais; (3) Se a instituição identificou o financiamento para o desenvolvimento de aplicativos de alta prioridade e serviços eletrônicos selecionados que irão maximizar Dados Abertos; (4) Se a instituição já tem alguns mecanismos de financiamento da inovação estabelecidos; (5) Se a instituição já investe em formação sobre as TIC para os seus funcionários públicos, e um conjunto de habilidades em tecnologia já existe nos principais departamentos para obter dados fornecidos por um portal de Dados Abertos; (6) Informações sobre os processos de financiamento; (7) Quaisquer fontes potenciais de financiamento para um programa de DA, incluindo o desenvolvimento e manutenção de um portal de DA para os primeiros anos, ou para desenvolver aplicativos selecionados de alta prioridade e serviços eletrônicos que irão impulsionar os DA; (8) Pormenores de quaisquer mecanismos de financiamento à inovação existente em DA.

\subsection{Tecnologia nacional e habilidades de infraestrutura}

Esta dimensão tem uma importância alta. Seu objetivo é avaliar a capacidade da infraestrutura nacional e da própria instituição, em termos de tecnologia e serviços de comunicações, bem como as competências dos funcionários em TIC, infomediários e público em geral. Pode ser coletada como evidência a lista de provedores de internet e serviços móveis e também: (1) Se a instituição já utiliza infraestruturas compartilhadas de TIC e compartilha serviços eletrônicos; (2) Se a maioria dos departamentos tem uma presença na Web; (3) Se departamentos individuais oferecem serviços eletrônicos, incluindo serviços habilitados para telefones móveis; (4) Se a penetração da Internet no país/localidade é robusta, ou seja, acima de $40 \%$.

\section{0 caso de uma instituição financeira pública brasileira}

A realização deste estudo de caso utilizou como instrumentos para a coleta de dados a investigação documental, questionários e observação.
A investigação documental foi efetuada em registros públicos disponíveis na internet e em certidões existentes no âmbito interno da instituição. De acordo com Yin (2001), o uso mais importante de documentos em estudos de caso é corroborar e valorizar as evidências oriundas de outras fontes.

As entrevistas foram realizadas de maneira semiestruturadas, gravadas em áudio e seguindo um roteiro prédeterminado pela metodologia ODRA. Esse procedimento teve a finalidade de captar a percepção de cada entrevistado sobre a prontidão da instituição para DA, observando o ponto de vista da especialidade do entrevistado.

\subsection{A instituição pesquisada e os participantes da pesquisa}

A escolha da instituição para a elaboração do estudo de caso deve-se às características de estar ligada à Administração Indireta e ser uma instituição financeira de grande porte, absolutamente pública, que age como agente de políticas públicas e parceira estratégica do Estado brasileiro. Sua sede está situada em Brasília/DF e abriga as áreas estratégicas da empresa, o Conselho Diretor e a Presidência.

Segundo o que consta na página da internet da instituição, a organização acredita que a informação pública pertence ao cidadão e que deve ser fornecida a ele pelo Estado. Por ser uma instituição pública, busca divulgar sempre de maneira clara e objetiva toda e qualquer informação de interesse coletivo ao disponibilizar dados importantes como os relacionados à empresa, os financeiros e os institucionais.

Como preparação para o estudo de caso foi feita uma análise do organograma da empresa, buscando identificar os atores relevantes segundo as definições da ODRA. A partir dessa análise, foram escolhidos para as entrevistas dois gestores responsáveis pela liberação de DA na instituição. Um, responsável pelo atendimento à LAI e à DA e o outro, responsável pelas questões de DA na área de TIC. A escolha buscou trazer as diferentes visões acerca do processo de DA na instituição, tanto no aspecto legal e político de liberação de DA, quanto na capacidade tecnológica atual da organização para essa liberação.

\subsection{A prontidão da instituição para a abertura de dados}

A seguir será apresentado o resumo da avaliação de cada dimensão, de acordo com a metodologia $O D R A$ adaptada, junto com as evidências coletadas para cada dimensão.

\subsubsection{Liderança Sênior}

Importância: Muito alta

Avaliação: VERDE 
+ A Instituição possui uma posição anunciada publicamente sobre Governo Aberto e a Lei de Acesso à Informação. Existe uma declaração aberta de que a Instituição acredita que a informação pública pertence ao cidadão e que deve ser fornecida a ele pelo Estado. Como empresa governamental, a Instituição busca divulgar sempre de maneira clara e objetiva toda e qualquer informação de interesse coletivo, levando a sério o direito dado pela LAI, ao acesso à informação pelo cidadão.

- Ainda não há uma posição clara da Instituição em relação a DA ou sobre o apoio da liderança em defesa da publicação dos dados seguindo os princípios de DA. Embora essa posição ainda não seja clara, a Presidente atual da Instituição, quando Ministra do Planejamento, cargo que ocupou antes de assumir a instituição em fevereiro de 2015, conduziu o Programa Brasileiro de DA e tem a capacidade de assumir essa liderança na Instituição.

+ Existe claramente um modelo de gestão com regências e papéis definidos, com áreas e responsáveis encarregados em apoiar e auxiliar a Instituição na liberação de informações, tanto no aspecto jurídico, como no aspecto técnico.

\subsubsection{Quadro Político / Legal}

\section{Importância: Alta}

\section{Avaliação: VERDE}

+ A LAI é o dispositivo legal mais amplo que a Instituição utiliza para a liberação de informações, ocupando um lugar de destaque em volumes de solicitação e atendimento às solicitações no âmbito da APF.

+ A Instituição obedece às legislações que amparam a proteção dos dados privados de seus clientes, repercutindo essas obrigações nas suas normas internas, de maneira a proteger a garantir a confidencialidade, de acordo com o grau de sigilo atribuído.

- As informações disponibilizadas pela Instituição, atualmente para download, contêm termos restritivos quanto à sua utilização e em alguns casos, necessitam de autorização para o seu uso.

- Por ser consignatária de informações e operar diversos sistemas, programas e fundos governamentais - por força contratual -, a Instituição não pode fornecer informações diretamente aos cidadãos de forma irrestrita, exceto quando constarem dos contratos de prestação de serviços.

\subsubsection{Estruturas Institucionais, Responsabilidades $e$ Habilidades Dentro da Instituição}

Importância: Alta

Avaliação: AMARELA
- Não existe uma designação claramente definida, de uma entidade capaz de liderar um programa de DA na Instituição. As informações disponibilizadas o são por iniciativas das áreas gestoras, em geral por imposição da LAI.

+ Há um forte apoio da Instituição em inovação, por meio de incentivos à capacitação e proposição de ideias inovadoras, mantendo parcerias com empresas de destaques no mercado.

- Não se localiza um departamento específico para DA e não foram encontradas evidências claras da introdução ou socialização de programas que promovam a ideia de DA em algum departamento da Instituição. Embora esses indícios não sejam claros, especificamente para DA, a Instituição promove e define claramente, por meio de áreas próprias, sua atuação no atendimento às questões de transparência de informações, em consonância com a LAI.

+ Existe um programa formal de treinamento para os funcionários da Instituição que aborda TIC e outras questões, seja por meio da Universidade Corporativa, com instrutores do quadro funcional ou contratação externa e incentivo à graduação, pós-graduação - lato e stricto sensu - e doutorado, bem como cursos técnicos em ferramentas de TIC.

+ Há uma vice-presidência, com estrutura específica de TIC, responsável pelos sistemas corporativos e infraestrutura de TIC e demais questões relacionadas às TIC na Instituição.

+ A Instituição promove interação com outros órgãos da APF, por meio de redes informais e eventos, de modo a melhorar as questões técnicas e ampliar a construção de habilidades nas questões de TIC.

5.2.4 Políticas Institucionais de Gerenciamento de, Processos e Disponibilidade de Dados

Importância: Alta

\section{Avaliação: VERDE}

+ A instituição mantém um inventário completo, atualizado e detalhado dos acervos de dados, com um processo forte e rígido de governança da informação e segurança dos dados, com áreas específicas para esse fim.

+ Existem evidências claras de políticas e normas coerentes de gestão de informação, aplicadas de forma coerente na Instituição para proteção e disciplina do uso dos ativos de informação da Instituição ou sob sua custódia, assegurando a confidencialidade, integridade, autenticidade e disponibilidade.

+ Há na Instituição, processos que promovem a digitalização de registros em conformidade com as normas internacionais, de maneira a garantir o acesso e a utilização dos dados. 


\subsubsection{Demanda por Dados Abertos}

Importância: Muito alta

Avaliação: AMARELA

+ Existem indícios claros de uma política formal da Instituição em mídias sociais e/ou no envolvimento do cidadão.

+ As evidências encontradas nessa pesquisa apontam que a Open Knowledge Foundation $(O K F)$ Brasil, a Universidade de São Paulo (USP) e a Universidade Federal de Santa Catarina (UFSC), desenvolvem pesquisas e aplicativos voltados para o uso de DA e capacitação do cidadão em DA.

- Não foram encontrados sinais de que a Instituição promove consultas participativas para informar as decisões políticas à sociedade. Entretanto, em relação ao Governo Federal existem portais mantidos pelo mesmo para consulta à sociedade, como o participa.br e o dialoga.gov.br.

5.2.6 Engajamento Cívico e Capacidades para Dados Abertos

Importância: Alta

Avaliação: VERDE

+ Há uma massa crítica de desenvolvedores de aplicativos no Brasil, que utilizam DA, como as ONGs $O K F$ Brasil, Contas Abertas, Deepask e Transparência Brasil, e se mantêm ativas em plataformas de mídias sociais ou por meio de atividades presenciais.

+ Existem evidências claras de promoção de eventos do tipo cocriação por parte do governo brasileiro com as comunidades de DA. Embora a Instituição não tenha participado desses eventos de maneira direta, existem evidências de patrocínio da Empresa a eventos de debates de Governo Aberto e DA.

+ A Instituição detém um histórico de envolvimento com os desenvolvedores na criação de aplicativos de serviços eletrônicos para os seus produtos e serviços. No campo de DA, não foram encontrados indicativos do envolvimento da Instituição com as comunidades de reutilizadores de DA.

+ Há sinais visíveis de disponibilidade de financiamentos de projetos iniciais para startups, pela Instituição e pelo Governo Federal.

+ Existem empresas com atividades econômicas que desenvolvem aplicativos, bem como um mercado crescente de uso, compra e download desses aplicativos. A instituição mantém o desenvolvimento de aplicações web e móvel, para uso dos seus clientes.

+ Há escolas técnicas e universidades com programas de ciência da computação que produzem um número notável de diplomados com cursos técnicos por ano. De acordo com o censo realizado pelo INEP/Ministério da
Educação, em 2013, existem 593 Instituições de Ensino Superior no Brasil, que oferecem cursos ligados à Ciência da Computação, onde foram licenciados 20.583 alunos no ano. Do total de alunos licenciados, cerca de $52 \%$ obtiveram formação em tecnólogo e o restante e licenciatura/bacharelado.

+ Encontram-se traços de um bom número de associações de jornalistas independentes, e a mídia controlada pelo Estado, tem uma menor força em relação à mídia privada.

\subsubsection{Financiamento de um Programa de Dados Aber-} tos

Importância: Média alta

\section{Avaliação: AMARELA}

+ Embora não tenham sido encontrados indícios nítidos sobre recursos específicos disponíveis para financiar um programa de DA, a Instituição já publica dados em seu site na Internet e também disponibiliza dados para que os ministérios contratantes os publiquem nos portais de transparência e DA do Governo Federal.

- Não existem evidências sobre a existência de projetos da Instituição para medir o retorno sobre o investimento para o custo de um programa de DA.

+ Por ser executora de diversos projetos e programas de governo voltados ao interesse social a Instituição tem a oportunidade de ampliar, por meio de DA, a transparência desses projetos e programas.

+ Há sinais evidentes sobre mecanismos de financiamento à inovação e ao investimento na formação em TIC para seus funcionários, bem como a existência de um conjunto de habilidades em tecnologias em toda a Instituição.

\subsubsection{Tecnologia Nacional e Habilidades em Infraes-} trutura

Importância: Alta

Avaliação: VERDE

+ Existem marcas tangíveis quanto à utilização compartilhada das infraestruturas de TIC e dos serviços eletrônicos pela Instituição.

+ A Instituição mantém um site da Internet com a presença da maioria das suas áreas de negócio.

+ Há indícios perceptíveis da existência de serviços eletrônicos, inclusive serviços habilitados para telefones móveis, em diversas áreas de negócios da Instituição.

+ Com a penetração da internet em 51,6\%, o Brasil ocupa a $5^{\mathrm{a}}$ colocação no ranking mundial, em quantidade absoluta de habitantes com acesso à rede mundial de computadores. Neste aspecto, a Instituição tem am- 
pliado a utilização da internet para prover serviços e informações aos seus clientes e à sociedade.

- O acesso à internet em banda larga ainda não é acessível para uma percentagem significativa da população. Com um custo médio de US\$16,62 ao mês, por $1 \mathrm{Mb} / \mathrm{s}$, faz com que o Brasil ocupe o $46^{\circ}$ lugar no ranking mundial. Entretanto, o Governo Federal, por meio do Programa Nacional de Banda Larga, criado pelo Decreto Presidencial $\mathrm{N}^{\mathrm{o}} 7.175$, de 12 de maio de 2010, pretende, dentre outros objetivos, massificar o acesso a serviços de conexão à Internet em banda larga.

+ As evidências coletadas indicam que a geração de empregos na indústria de TIC brasileira, incluindo o desenvolvimento de software, é considerável e corresponde a $2,95 \%$ do PIB no $2 \% / \mathrm{T} / 2015$. Como resultado dessa força, a geração de empregos no setor é notável e corresponde a 472 mil trabalhadores na última pesquisa PAS/IBGE - 2012.

\section{Discussão dos resultados}

O estudo de caso realizado com a utilização da metodologia ODRA adaptada para o contexto institucional público brasileiro demonstrou sua viabilidade prática. Foi possível evidenciar os pontos positivos e os que necessitam de aprimoramento, para que a instituição possa disponibilizar os seus dados para reutilização pela sociedade.

\subsection{Preparação para aplicação da metodologia $O D R A$}

Como já explicitado neste trabalho, para a aplicação da metodologia $O D R A$ foi efetuada uma análise prévia das informações e dados disponibilizados no sítio da instituição na internet e nos dos principais Ministérios/Órgãos da APF com os quais a organização mantém contratos de prestação de serviços. Em seguida foram analisados aspectos legais e políticos sobre a liberação de DA pela instituição.

É importante ressaltar que o fato de um dos pesquisadores ser empregado da instituição investigada e ter amplo conhecimento sobre os diversos processos internos e da sua estrutura organizacional, contribuiu para a identificação dos entrevistados, para a coleta de informações e para o levantamento das evidências indicadas pela $O D R A$

6.2 Pontos fortes e oportunidades de melhorias da ODRA

Pela sua flexibilidade, a $O D R A$, apresenta pontos positivos ao permitir ajustes que levam em conta a especificidade de cada instituição, governo ou país e aponta, de maneira não exaustiva, caminhos a serem percorridos pelo avaliado, a fim de obter os bons resultados advindos da implantação de uma iniciativa ou um programa de DA. Portanto, a metodologia se mostrou vantajosa, por não ser monolítica e inflexível, pelo contrário, a sua adaptabilidade permite que se mantenha a essência dos fundamentos que devem existir para que uma iniciativa ou um programa de DA seja exitoso.

Foi observado que alguns pontos da metodologia $O D R A$ não puderam ser aplicados somente no escopo da instituição, uma vez que as questões são relacionadas a assuntos de competência do Governo Federal. Portanto, por não ter uma relação direta com a instituição, apresenta limitações para atuação da mesma. Apesar disto, essas questões foram respondidas levando em conta aspectos particulares da instituição e o cenário nacional.

6.3 Diagnóstico final da prontidão da instituição avaliada

A análise da prontidão da instituição demonstrou que existem lacunas a serem preenchidas em relação: ao posicionamento claro da liderança; ao estabelecimento de uma cultura organizacional em DA e não somente em Governo Aberto; ao maior envolvimento da instituição com a comunidade e público de interesse de maneira ativa; à ampliação das discussões com os gestores dos dados consignados para que estes sejam disponibilizados diretamente pela instituição; e à ampliação e maior disponibilização dos dados em formato aberto, seguindo os padrões de DA. Abaixo elencamos os principais pontos e o resultado final de cada uma das oito dimensões avaliadas.

\subsubsection{Liderança Sênior (VERDE)}

Está claro nas informações e evidências coletadas que a alta administração ainda não se posicionou publicamente em relação à disponibilização ou não dos dados da instituição como DA. Além disso, não é visível o apoio para DA entre os principais departamentos proprietários e consignatários de dados. Embora esses pontos possam ser considerados como lacunas existentes, a avaliação considerou positivo o fato de a instituição ter uma posição definida em relação ao Governo Aberto e a LAI.

Outro aspecto bastante relevante na avaliação dessa dimensão é a contribuição que o contexto político e as prioridades/planos da instituição têm no apoio à liberação de informações e dados, pois há um modelo claro de gestão, com liderança e papéis definidos para as suas áreas.

De acordo com a metodologia, quando se verifica a existência de, pelo menos, apoio público da liderança para DA e a identificação do dirigente que é responsável por questões de direito à informação e Governo Aberto, esta dimensão pode ser classificada como VERDE. Assim, por existirem evidências claras de apoio da instituição ao Governo Aberto e à LAI, bem como a definição dos papéis de cada liderança para a liberação de dados e informações, esta dimensão foi avaliada com a classificação VERDE. 


\subsubsection{Quadro Político / Legal (VERDE)}

As evidências coletadas demonstram a existência e eficácia de uma lei de acesso à informação, a LAI, e uma lei de proteção da privacidade, a Lei do Sigilo Bancário. Ambas têm abrangência nacional e estão relacionadas respectivamente às instituições públicas e às instituições financeiras. A instituição também possui sistemas de segurança, preservação e arquivamento de dados, protege a propriedade, o licenciamento de dados do governo e a venda dos mesmos.

Para esta dimensão avaliamos a instituição como VERDE, pois a metodologia assim indica quando há evidências claras da existência de legislação regulamentando o acesso à informação, a proteção da privacidade e do anonimato e processos de gestão com regras claras que estabelecem padrões nos sistemas de segurança, banco de dados e redes.

\subsubsection{Estruturas Institucionais, Responsabilidades $e$ Habilidades Dentro da Instituição (AMARELA)}

Embora não exista um departamento específico na instituição que trate de DA e não tenham sido encontradas evidências claras sobre a introdução ou socialização de programas, que promovam a ideia de DA em algum departamento da instituição, foi considerado positivo o fato da instituição ter definido áreas específicas para o atendimento das questões de transparência de informações, em consonância com a LAI.

Nas demais questões avaliadas nesta dimensão foram encontradas evidências de que há um forte apoio da instituição à inovação, capacitação dos seus funcionários, designação de área específica com representação na alta administração para tratar das questões de TIC e a promoção de interação da instituição com outros órgãos da APF, visando melhorar questões técnicas e ampliar a construção de habilidades em TIC.

De acordo com a metodologia, consideramos que a instituição apresenta uma classificação AMARELA na avaliação desta dimensão, uma vez que não existe uma manifestação clara de uma área com peso político e competências suficientes na liderança de um programa de DA. Apesar disto, há evidências que demonstram um forte histórico na coordenação de TIC, apoio da instituição à inovação e capacitação dos seus funcionários, interação com outros órgãos da APF sobre mecanismos e iniciativas de GA e a existência de uma VicePresidência responsável pelas decisões estratégicas e gestão das TIC.

\subsubsection{Políticas institucionais de gerenciamento de da-} dos, processos e disponibilidade de dados (VERDE)

Existem evidências claras de como e onde os dados são guardados e atualizados pela instituição, do controle dos departamentos sobre suas coleções de dados e da capacidade de gerenciamento de dados dos departamentos proprietários de dados chaves.
À luz da metodologia, consideramos que nesta dimensão a instituição tem uma classificação VERDE, pois seus dados de alto valor já estão disponíveis em formato digital, guardados e atualizados para que possam ser extraídos e disponibilizados por máquinas. Também, as evidências demonstram que existem políticas e normas coerentes de gestão da informação que disciplinam e protegem o uso dos ativos de informação da instituição ou sob a sua custódia, de maneira a assegurar a confidencialidade, integridade e disponibilidade destes.

\subsubsection{Demanda por Dados Abertos (AMARELA)}

Não foram encontradas evidências sobre consultas participativas, promovidas pela instituição para comunicar as decisões políticas à sociedade. Apesar disto, existem evidências de que o Governo Federal promove iniciativas no sentido de ouvir e permitir a participação da sociedade em suas decisões.

Também não existem evidências claras sobre demandas por DA dirigidas à instituição, promovidas por infomediários buscando o desenvolvimento de aplicativos. Apesar disto, foram encontradas evidências do uso de dados produzidos ou consignados à instituição, por infomediários, e de iniciativas destes, na promoção de pesquisas e capacitação da sociedade no tema DA.

Nesta dimensão, de acordo com a metodologia, avaliamos que a instituição tem uma classificação AMARELA, pois há evidências de demanda de dados pela LAI e alguns departamentos têm canais de pronta resposta para as solicitações e atualizações de dados.

6.3.6 Engajamento Cívico e Capacidades para Dados Abertos (VERDE)

A avaliação desta dimensão não levou em consideração tão somente as evidências da instituição, pois o engajamento cívico e capacidades para DA necessitam de uma visão ampliada sobre o envolvimento de todo o governo. Assim, as questões foram respondidas olhando tanto o aspecto das evidências da instituição, quanto em relação ao Governo Federal.

Foram levadas em considerações a existência de evidências claras de uma massa crítica de desenvolvedores de aplicativos no Brasil, que se utilizam de DA, do envolvimento do Governo Federal com as comunidades de DA e do patrocínio pela instituição em eventos de Governo Aberto e DA promovidos pelo Governo Federal. Além disso, há evidências de uma ampla gama de escolas técnicas e universidades no país, que produzem pesquisas avançadas e colaboram em projetos de TIC.

De acordo com a metodologia aplicada, a instituição pode ser classificada como VERDE, levando em consideração o seu alinhamento com as ações do Governo Federal, o histórico do envolvimento da instituição com desenvolvedores para a criação de aplicativos, de 
maneira a fomentar o desenvolvimento da indústria local de TIC.

\subsubsection{Financiamento de um Programa de Dados Aber- tos (AMARELA)}

Não existem evidências claras sobre a existência de recursos específicos da instituição para o financiamento de um programa de DA e sobre projetos da instituição que objetivam medir o retorno do investimento para um programa de DA. Apesar disto, a instituição já publica em seu sítio na internet dados importantes para acesso ao público e também disponibiliza dados a ela consignados, para que os Ministérios contratantes os disponibilizem em seus sítios, nos portais de transparência e de DA do Governo Federal.

De acordo com a metodologia, a instituição tem uma classificação AMARELA, uma vez que a instituição está preparada para considerar um orçamento para DA, mesmo que este ainda não esteja comprometido. Além disso, a instituição, mesmo com recursos limitados, consegue fazer investimentos em inovação.

\subsubsection{Tecnologia Nacional e Habilidades de Infraestru- tura (VERDE)}

Para avaliação desta dimensão foram consideradas, principalmente, as evidências do Governo Federal, uma vez que este é responsável pelas políticas nacionais que afetam todo o ecossistema de TIC do país. Além disto, alguns aspectos avaliados levam em consideração o âmbito da instituição e seus departamentos.

Existem evidências claras quanto ao acesso em massa à internet de alta velocidade e móvel, uma maturidade no uso de tecnologias e sobre a infraestrutura nacional de TIC, em especial no compartilhamento da infraestrutura e dos serviços. Além disso, existe uma crescente cultura de TIC entre a população e uma indústria local de TIC em desenvolvimento.

Assim, de acordo com a metodologia, a instituição tem a classificação VERDE, pois além de estar inserida no contexto nacional, compartilha internamente as suas infraestruturas e serviços de TIC e mantém uma forte presença na internet, inclusive com a disponibilização de aplicativos para telefones móveis, voltados para prestação de serviços e informação aos cidadãos.

\section{Conclusão e trabalhos futuros}

É inegável que a disponibilização de dados governamentais como DA amplia a capacidade de participação do cidadão no acompanhamento das ações e gastos dos governos. A transparência proporcionada pelos DA fortalece a democracia na medida em que toda a sociedade pode participar das discussões.

Os ganhos com a utilização de DA não se restringem apenas ao controle social e à transparência democrática. Os DA também proporcionam ganhos econômicos, na medida em que estimulam o desenvolvimento da indústria de TIC, com alto potencial de geração de valor e de criação de novos negócios.

Este trabalho demonstrou que o Brasil também está inserido no contexto mundial de DA e segue uma tendência consolidada nos países democráticos mais amadurecidos, estabelecendo fundamentos para a disponibilização de DA. Existe muito a se fazer por parte do governo brasileiro, como legislação clara em relação ao direito de uso dos dados pelos públicos de interesse, a ampliação da disponibilidade, tempestividade e utilidade dos dados pelos órgãos públicos e ministérios, e ainda, uma maior vontade política das lideranças, com discursos, recursos financeiros específicos e normas claras, para que os DA sejam realmente uma realidade no país.

Esse balanço do estágio atual dos DA no Brasil que este trabalho trouxe foi seguido de um aprofundado estudo da questão da prontidão das instituições públicas para a abertura de dados, pois é o estágio de prontidão hoje demonstrado pela administração pública que indicará qual o cenário futuro da abertura de dados governamentais no Brasil. Como demonstrado, a avaliação da prontidão para a abertura de dados não se refere apenas ao estágio inicial e deve ser evoluída constantemente para que se atinjam os resultados esperados.

Neste sentido, a contribuição central deste trabalho foi traduzir e adaptar para o contexto da administração pública brasileira uma metodologia testada e reconhecida internacionalmente de avaliação da prontidão para a abertura de dados governamentais. A adaptação proposta foi ainda validada por meio de um estudo de caso em uma grande instituição financeira pública brasileira, comprovando sua aplicabilidade.

Vale a pena ressaltar que o estudo de caso realizado é por si mesmo um marco ao atacar a questão da abertura de dados e da transparência na Administração Pública Indireta e mais ainda, num nicho bastante atípico que é o das instituições financeiras públicas.

O estudo da prontidão para a abertura de dados na Administração Indireta toma outra dimensão dada a sua diversidade e descentralização. Se na Administração Direta é possível discutir a prontidão no nível de Estado ou de grandes órgãos superiores, onde a cadeia de comando e os processos decisórios são mais homogêneos e bem estabelecidos, na Administração Indireta é preciso descer a análise para o nível das instituições, já que essas possuem outro grau de autonomia administrativa e, embora estejam vinculadas à Administração Direta, possuem elevado grau de independência em seus processos decisórios.

Mas além de pertencer à Administração Indireta, a instituição pública estudada atua no setor financeiro. No Brasil, as instituições financeiras públicas têm como missão apoiar o Governo no desenvolvimento econômico e social. Como integrantes da Administração In- 
direta, estão subordinadas à LAI, mas como instituições financeiras têm os seus dados protegidos pela Lei do Sigilo Bancário. Essa combinação de contextos e legislações define um contexto complexo e peculiar que desafia os princípios da transparência e da abertura de dados.

O sucesso na condução dessa análise de prontidão institucional para abertura de dados prova que a abertura de dados governamentais de interesse da sociedade pode e deve ser discutida em qualquer esfera, qualquer nível e qualquer nicho da administração pública.

Assim, como trabalhos futuros, entendemos que a avaliação da prontidão para abertura de dados deve ser incentivada e promovida na APF brasileira, em todos os níveis e esferas, de maneira a contribuir com o avanço e o amadurecimento das iniciativas de DA.

Finalmente, esperamos que este trabalho possa contribuir de maneira positiva, na ampliação da gestão do conhecimento sobre DA no Brasil, bem como apresentar alternativas de avaliação da prontidão de instituições da APF no campo de DA.

\section{Notas}

(1) Termo citado por John Hagel, formado pelas palavras informação e intermediário.

\section{Referências}

Beghin, N.; Zigoni, C. (Org) (2014). Avaliando os websites de transparência orçamentária nacionais e sub-nacionais e medindo impactos de dados abertos sobre direitos humanos no Brasil. Brasilia, DF: Instituto de Estudos Socioeconômicos (INESC), 2014.<http://www.inesc.org.br/biblioteca/

publicacoes/textos/pesquisa-transparencia-orcamentaria-noswebsites-nacionais-e-sub-nacionais> (11-11-2014)

Brasil. (2001). Lei Complementar $\mathrm{N}^{\circ}$ 105, de 10 de janeiro de 2001. Dispõe sobre o sigilo das operações de instituições financeiras e dá outras providências // Diário Oficial [da] República Federativa do Brasil. Brasilia, DF, 11/01/2001. http://pesquisa.in.gov.br/

imprensa/jsp/visualiza/index.jsp?data=11/01/2001\&jornal=1\&pa gina $=1 \&$ totalArquivos=160 (02-11-2015)

Brasil. (2012). Instrução Normativa $\mathrm{n}^{\circ}$ 4, de 12 de abril de 2012. Institui a Infraestrutura Nacional de Dados Abertos - INDA // Diário Oficial [da] República Federativa do Brasil. Brasilia, DF, 13/04/2012.http://pesquisa.in.gov.br/imprensa/jsp/visualiza/ index.jsp?jornal $=1 \&$ pagina $=67 \&$ data $=13 / 04 / 2012(30-05-2015)$

Cavalcanti, J. M. M. et. al. (2013). Observância da lei de acesso à informação pelas autarquias federais do Brasil // Perspectivas em Ciência da Informação [online] 18: 4 (2013) 112-126. <http://www.scielo.br/pdf/pci/v18n4/08.pdf> (18-5-2014)

Dassen, N.; Juan, C. V. (2012). Open government and targeted transparency: Trends and challenges for Latin America and the Caribbean. Washington, DC: Inter-American Development Bank, 2012. http://idbdocs.iadb.org/wsdocs/getdocument. aspx?docnum=37245826 (22-03-2015).

Davies, T. (2014). ODDC Update at Developers for Development. Montreal, CA: World Wide Web Foundation, 2014. <http://www.timdavies.org.uk/2014/01/28/oddc-update-atdevelopers-for-development-montreal/> (25-11-2014).
Davies, T. et al. (2015). Open Data Barometer Global Report. Washington, DC: World Wide Web Foundation, 2015. <http://opendatabarometer.org/assets/downloads/Open Data Barometer - Global Report - 2nd Edition - PRINT.pdf> (05-022015)

Dietrich, D. et al. (2012). Open Data Handbook Documentation. Cambridge, UK: Open Knowledge Foundation, 2012. <http://opendatahandbook.org/en/> (08-05-2014)

Edelmann, N. et al. (2012). Collaboration for Open Innovation Processes in Public Administrations // Empowering Open and Collaborative Governance. Berlim, Heidelberg: Springer, Berlim Heidelberg, 2012. 21-37. <http://link.springer.com/10.1007/9783-642-27219-6> (27-05-2014).

Freitas, R. K.V.; Dacorso, A. L. R. (2014). Inovação aberta na gestão pública: análise do plano de ação brasileiro para a Open Government Partnership // Revista de administração pública [online] 48: 4 (2014) 869-888 http://bibliotecadigital.fgv.br/ojs/index.php/rap/article/view/3088 0/29700> (22-10-2016)

Geiger, C. P.; Lucke, J. Von. (2012). Open Government and (Linked) (Open) (Government) (Data) // Journal of Democracy 4:2 (2012) 265-278. <http://www.jedem.org/article/view/143/115> (22-032015).

Gurin, J. (2014). Open Data Now: The Secret to Hot Startups, Smart Investing, Savvy Marketing, and Fast Innovation. $1^{\text {a }}$ ed McGraw-Hill Education, New York, 2014. http://www.amazon.com.br/dp/B00HUTE4C4 (20-04-2015).

Machado Júnior, Francisco Tanajura. (2015). Avaliação da prontidão para a abertura de dados das instituições públicas brasileiras: um estudo de caso de uma instituição financeira pública brasileira // Dissertação (Mestrado) Universidade Católica de Brasília, 2015. <http://www.bdtd.ucb.br/tede/tde_busca/arquivo.php?codArquiv $\mathrm{o}=2383>$. (29-11-2016)

Mencarini, F. (2015). Transparência nos Bancos Públicos Brasileiros: um estudo sobre a implementação da Lei de Acesso à Informação (LAI) no Banco do Brasil (BB), Caixa Econômica Federal (CEF) e Banco Nacional de Desenvolvimento Econômico e Social (BNDES). São Paulo, SP: Fundação Getúlio Vargas (FGV), Escola de Administração de Empresas de São Paulo, 2015. <http://hdl.handle.net/10438/13602>. (18-08-2015)

Modesto, L.R.; Ferneda, E.; Sant'ana, R.C.G. (2014). Representação e persistência de recursos informacionais digitais gerados dinamicamente em sítios oficiais do Governo Federal // Brazilian Journal of Informaiton Science [online] 8: 1/2 (2014) 1-24. http://www2.marilia.unesp.br/revistas/index.php/bjis/article/view /4252/3091>. (22-10-2016).

Ramírez-Alujas, Á. (2012). Open Government and Public Management Modernization: A New Paradigma, 2012. <http://www.inap.mx/portal/images/pdf/iica/ ponencias/4/Ramirez-Alujas.pdf>. (22/03/2015).

Sandoval-Almazán, R. (2011). The Two Door Perspective: An Assessment Framework for Open Government // Journal of Democracy $\quad 3: \quad 2018$ (2011) <http://www.jedem.org/article/view/67/86>. (22-03-2015).

United Nations (Un). (2014) United Nations e-Government Survey 2014: E-Government for the Future We Want. United Nations, New York, 2014 <http://unpan3.un.org/egovkb/Portals/egovkb/Documents/un/201 4-Survey/E-Gov_Complete_Survey-2014.pdf> (21-11-2014).

World Bank. (2013). Open Data Readiness Assessment tool. The World Bank, Open Government Data Working Group, Washington, DC, 2013. <data.worldbank.org/ogd>. (21-112014) 
World Bank. (2015). Open Data Readiness Assessment (ODRA): Methodology (Part B). World Bank, Washington, DC, 2015. <http://opendatatoolkit.worldbank.org/docs/odra/odra_v3.1_met hodology-en.pdf>. (08-05-2015)

Yin, R. K. (2001). Estudo de caso: planejamento e métodos. 2a Ed. ed.Porto Alegre: Bookman, 2001.

Yu, H.; Robinson, D. G. (2012) The New Ambiguity of "Open Government" // UCLA Law Review Discourse 5 (2012) 178208. <http://www.uclalawreview.org/?p=3663> (26-01-2015).

Zymler, B. (2014). Relatório de Levantamento - TC 005.003/20148. Tribunal de Contas da União, Brasilia, DF, 2014. http://www.tcu.gov.br/Consultas/Juris/Docs/judoc/Acord/20141 006/AC_2569_38_14_P.doc (28/03/2015).
Copyright: () 2018 Machado Júnior (et al.). This is an open-access article distributed under the terms of the Creative Commons CC Attribution-ShareAlike (CC BY-SA), which permits use, distribution, and reproduction in any medium, under the identical terms, and provided the original author and source are credited.

Received: 2016-11-29. Accepted: 2017-06-27 